\title{
Las formas de tratamiento en el teatro rioplatense realista de principios del siglo XX y su variación desde una perspectiva pragmática y sociocultural
}

\author{
Forms of treatment in the realistic river plate \\ theater of the early $20^{\text {th }}$ Century and its variation \\ from a pragmatic and a sociocultural perspective
}

\author{
María de los Ángeles Corradi \\ Universidad Nacional de Río Cuarto, Río Cuarto, Córdoba, Argentina \\ mdacorradiehum.unrc.edu.ar
}

ACCESO ABIERTO / OPEN ACCESS

Cita: Corradi, María de los Ángeles (2021). Las formas de tratamiento en el teatro rioplatense realista de principios del siglo XX y su variación desde una perspectiva pragmática y sociocultural. Textos en Proceso, 7(1), pp. 60-75.

https://doi.org/10.17710/tep.2021.7. 1.4corradi

Editoras: Esperanza Alcaide Lara (Universidad de Sevilla) y Ana Pano Alamán (Università di Bologna)

Recibido: 20/03/2021

Aceptado: 15/07/2021

Conflicto de intereses: La autora ha declarado que no posee conflicto de intereses.

Copyright: @ María de los Ángeles Corradi. Esta obra está bajo licencia Creative Commons Reconocimiento 4.0

\section{Resumen}

Esta investigación tiene por objetivo analizar la alternancia en las formas de tratamiento como una estrategia de variación pragmática capaz de vehiculizar las intenciones (des)corteses del emisor en un corpus de textos dramáticos argentinos de principios del siglo XX. Aplicamos un enfoque teórico pragmático-sociocultural para el análisis de un corpus de 17 obras de teatro en las cuales identificamos un total de 40 ejemplos de alternancia en las formas de tratamiento. Para este trabajo seleccionamos solo 10 de esos ejemplos, que consideramos los más representativos de nuestro análisis. La mayoría de los casos de alternancia documentados en nuestra investigación pudieron pensarse bajo el amparo de la tipología acuñada por Kaul de Marlangeon (2011), pero para los demás tuvimos que elaborar categorías propias. Los resultados nos permitieron agrupar los ejemplos de alternancia en tres grandes grupos: aquellos que evidencian variación pragmática en el ámbito de la cortesía, los que manifiestan variación pragmática en el ámbito de la descortesía y, finalmente, los casos

Palabras clave: formas de tratamiento; variación pragmática; (des)cortesía; textos dramáticos.

\begin{abstract}
This research aims to analyze the alternation in the forms of treatment as a strategy of pragmatic variation capable of conveying the (im)politeness intentions of the issuer in a corpus of Argentinian dramatic texts from the early twentieth century. We apply a pragmatic-sociocultural theoretical approach to a corpus of 17 plays in which we identify a total of 40 examples of alternation in the forms of treatment.
\end{abstract}


We select only 10 of those examples for this work, which we consider the most representative of our analysis. Most of the examples could be analyzed applying the typology coined by Kaul de Marlangeon (2011), but for the others we had to develop our own categories. The results allowed us to group the examples of alternation into three large groups: those that show pragmatic variation in the field of politeness, those that show pragmatic variation in the field of impoliteness and, finally, the cases in which alternation in politeness forms of treatment do not show pragmatic variation.

Keywords: forms of treatment; pragmatic variation; (im)politeness; dramatic texts.

\section{Introducción}

El objetivo del presente trabajo es analizar la dimensión pragmática de las formas de tratamiento como un fenómeno que pertenece al ámbito de la (des)cortesía verbal en una variedad del diasistema del español constituida por el español rioplatense de principios del siglo XX. Con ese propósito construimos un corpus que está conformado por textos dramáticos que se inscriben dentro de la corriente realista y fueron publicados en ese período de tiempo.

Concebimos la alternancia entre las formas de tratamiento vos-usted como un fenómeno de variación (Lavandera, 2014) porque el hablante se vale de esta selección para alcanzar sus propósitos comunicativos. En este sentido, Kaul de Marlangeon (2011) especifica aún más este concepto al hablar de variación pragmática en las formas de tratamiento cuando esta tiene lugar en el eje sintagmático, es decir, cuando la alternancia se emplea en el mismo texto y para referirse al mismo receptor. En esos casos, el mecanismo lingüístico de la alternancia opera como una estrategia de (des)cortesía en manos del hablante sujeta a las premisas culturales de su comunidad.

Para poder determinar el valor pragmático de la alternancia en cada uno de los ejemplos que integran nuestro corpus es necesario llevar adelante un análisis interpretativo con el objetivo de fundamentar la aparición de cierto uso en determinado contexto y extraer conclusiones acerca de las motivaciones socioculturales que permiten justificar el empleo de la alternancia como estrategia de variación pragmática.

Nuestra hipótesis preliminar es que la distinción tradicional establecida por la NGLE (2009, p. 1250) entre el uso de confianza vos y el empleo del pronombre formal usted como forma de respeto resulta apropiada en lo fundamental, pero tiene sus limitaciones en lo que hace al análisis e interpretación de nuestro corpus. Las siguientes variables de orden sociocultural, también reconocidas por la NGLE (2009, p. 1250), pueden resultar más orientadoras: la relación social entre emisor y receptor, la confianza que existe entre los interlocutores, la cercanía, la solidaridad, la intimidad, el respeto, el nivel del que recibe el trato en relación con el de quien se lo otorga, la situación comunicativa y su grado de formalidad, y otros aspectos como estos. 


\section{Marco teórico}

\subsection{Categorías de variación sociocultural}

Este trabajo de investigación se enmarca en un enfoque teórico pragmáticosociocultural (Bravo, 2005). Asumir ese posicionamiento implica reconocer que el estudio de la alternancia en las formas de tratamiento, como un fenómeno que pertenece al ámbito de la (des)cortesía, no puede prescindir de las consideraciones que derivan del estudio del "contexto del usuario de la lengua" (Bravo, 2003, p. 99).

Hay tres nociones que son características del enfoque pragmáticosociocultural y que queremos retomar porque resultan pertinentes para el análisis de nuestro corpus. Se trata de las categorías de contexto relevante, premisas socioculturales y comunidad sociocultural.

Según Bravo (2005, p. 37), la elección del objeto de estudio es lo que determina el tipo de contexto relevante para su interpretación. En el ámbito de los estudios sobre cortesía, el interés se desplaza de aquello que quiso decir el hablante -significado del hablante- hacia los efectos sociales de ese comportamiento comunicativo en la relación interpersonal -significado del usuario-. Como afirma Bravo (2005, p. 38): "Es el significado del usuario, o sea, lo que el mensaje quiere decir habitualmente en esa comunidad socio-cultural, lo que constituye el contexto distintivo para los estudios de la cortesía" y, por lo tanto, resulta imprescindible dejar ingresar el factor extralingüístico como parte de la metodología de análisis.

La incorporación del elemento extralingüístico como categoría de análisis trae consigo la noción de premisas socioculturales (Bravo, 2005, p. 44). Cuando el analista pertenece a la misma comunidad sociocultural de referencia de los hablantes en estudio, puede apelar a sus propias experiencias comunicativas como miembro de esa comunidad para llevar a cabo su labor interpretativa. Sin embargo, si no quiere "correr el riesgo de caer en interpretaciones etnocéntricas" (Bravo, 2005, p. 53), debe explicitar las premisas socioculturales que subyacen a su interpretación. Y esto implica poner de manifiesto aquellas "creencias, normas sociales y valores culturales" (Bravo, 2005, p. 53) de los cuales el hablante no es usualmente consciente pero que intervienen en su interpretación de los comportamientos comunicativos.

La explicitación de las premisas socioculturales debe formar parte de la metodología de los analistas y estas pueden convertirse en categorías para el análisis porque suponen una referencia consciente a aquellos conocimientos que el investigador comparte con los demás hablantes de su comunidad sociocultural y justifican "sus interpretaciones acerca del efecto social de los comportamientos comunicativos en estudio" (Bravo, 2005, p. 44).

También nos parece pertinente retomar la noción de "comunidad sociocultural", que Bravo desarrolla como una reformulación del concepto de "comunidad de habla" acuñado por Hymes (Bravo, 2005, p. 31). Cuando esta autora quiere dar cuenta de la pertenencia de un hablante real a una comunidad con la cual comparte ciertas normas y convenciones acerca de los comportamientos comunicativos que se aguardan como naturales, prefiere el concepto de "comunidad sociocultural" por sobre el de "comunidad de habla" porque considera que este tiene la virtud de incorporar dentro de sí "las nociones de comunidad de lengua, identidad de grupo y pertenencia sociocultural".

Otro de los mojones teóricos en los que se sustenta nuestro trabajo es la sociolingüística de la variación (Lavandera, 2014). Los aportes de esta corriente nos 
permiten pensar el fenómeno de la variación como una característica inherente del lenguaje en uso que puede ser objeto de un estudio sistemático, como el resultado de "una elección funcional de parte del hablante, dirigida a servir sus propósitos comunicativos" (Lavandera, 2014, p. 8).

Lavandera distingue la variación en el eje paradigmático de la variación en el eje sintagmático. En el primer caso, hablamos de la sustitución en un mismo espacio de formas alternantes. Por ejemplo, cuando decidimos emplear la forma de tratamiento vos en lugar de usted para dirigirnos a un colega. Mientras que en el segundo caso nos hallamos en presencia de un cambio secuencial de una forma a su alternante. Esto sucede cuando en un mismo intercambio empleamos dos formas alternantes para dirigirnos al mismo interlocutor, es decir, lo tratamos primero de usted y luego de vos, o viceversa.

En el presente artículo nos centraremos en la variación que se produce en el eje sintagmático, porque es la que da cuenta del "paso del empleo de una forma gramatical o léxica a otra forma del mismo sistema" (Lavandera, 2014, p. 12). Sin embargo, es válido aclarar que no en todos los casos de variación en el eje sintagmático constituyen variación pragmática.

Kaul de Marlangeon (2011, p. 218) define el concepto de variación pragmática como "la variación que se produce en el uso del lenguaje en contexto y que se puede examinar con respecto a diferentes ámbitos de categorización (...): el ilocutivo, el discursivo, el de participación, el estilístico y el no verbal". La cuestión de la que se ocupa luego es la siguiente: ¿cuándo o en qué contextos la alternancia en las formas de tratamiento constituye variación pragmática y cuándo no? A lo cual concluye que "hay variación pragmática (...) cuando el hablante usa la alternancia en un mismo texto dirigido al mismo receptor" (Kaul de Marlangeon, 2011, p. 224). La alternancia no constituye variación pragmática cuando es el vehículo de la doble dirección del emisor hacia distintos receptores y tampoco cuando la alternancia de las formas de tratamiento entre los interlocutores es constante según roles. Para esta autora la variación pragmática se limita a aquellos contextos en los cuales la alternancia constituye una estrategia de (des)cortesía sujeta a las premisas culturales de una cultura y comunidad determinadas.

\section{2. Paradigmas pronominales voseantes}

En la variedad dialectal rioplatense el sistema pronominal de segunda persona contempla dos únicas formas para el singular que, en un principio, diremos que se oponen por su grado de formalidad: vos y usted.

La parte pronominal del paradigma vos incluye las formas: vos (sujeto o término de complemento), te (objeto o reflejo), tu/s (adjetivo posesivo) y tuyo/a/os/as (sustantivo posesivo). La parte verbal del paradigma toma las terminaciones de la segunda persona del singular, que son las mismas que las de tú, salvo en el presente indicativo, que asume formas monoptongadas en -ás, -és, -ís, en el presente subjuntivo (podás) y en el modo imperativo (sentate).

La parte pronominal del paradigma usted incluye las formas: usted (sujeto o término de complemento), lo/la/le (objeto), se (reflejo) y su/sus-suyo/a/os/as (posesivo). Con excepción del nominativo usted, todas las formas pronominales, así como las inflexiones verbales son homónimas de la tercera persona del singular.

En este paradigma la forma vos está totalmente generalizada y no existe ningún tipo de alternancia o contraste con tú, que resulta completamente ajeno a la comunidad. Lo que es más, en palabras de Fontanella de Weinberg (1999, p.1408), 
su utilización indicaría "procedencia extranjera, afectación, pretenciosidad o pedantería".

¿Qué puede decirse de la dimensión pragmática de las formas de tratamiento? Nos referimos, primordialmente, a la oposición en el uso entre los tratamientos de confianza: uso del pronombre informal vos y los tratamientos de respeto: uso del pronombre formal usted. A este respecto, la $\operatorname{NGLE~(2009,~p.~1250)~reconoce~que~}$ esta distinción tradicional se sigue considerando apropiada en lo fundamental, aunque advierte sobre sus limitaciones. En la elección de las formas de tratamiento intervienen también otros factores como la relación social que existe entre el emisor y el receptor, la confianza que exista entre los interlocutores, la cercanía, la solidaridad, la intimidad, el respeto, el nivel del que recibe el trato en relación con el de quien se lo otorga, la situación comunicativa y su grado de formalidad, y otros aspectos similares.

Aiola y Degli Uomini (2014, p. 115) retoman a Maingueneau para poner en tela de juicio el hecho de que el uso de usted constituya en todos los casos una demostración de respeto. Afirman que "el tratamiento de vos puede ser el requerido en un determinado contexto y no una forma de menor cortesía, y, por el contrario, se puede tratar de usted para marcar la exclusión, la puesta en distancia, y no por respeto".

Las formas de tratamiento "son parte integrante de todo ese conjunto de reglas sociales que rigen el comportamiento verbal de los miembros de una comunidad y que son específicas de cada cultura" (Medina López, 2005, p. 99). En otras palabras, esto significa que la selección de las formas de trato no depende exclusivamente de la preferencia individual del hablante, sino que está sujeta a las imposiciones sociales de su comunidad. Es por ese motivo que la alternancia, como portadora de sentidos socialmente definidos, "no se circunscribe a un texto particular, sino que abarca a todos los análogos posibles (...) su alcance es social o general, como expresión de la conducta social de la comunidad estudiada. Se trata (...) de estrategias inherentes a un determinado tipo de textos o de situaciones discursivas dentro de la misma cultura" (Kaul de Marlangeon, 2011, p. 237).

\subsection{El fenómeno de las formas de tratamiento}

En una serie de investigaciones que consideramos los antecedentes inmediatos del presente trabajo, Kaul de Marlangeon $(2010,2011)$ se ocupa de la temática específica de la alternancia en las formas de tratamiento y la sitúa en el eje de estudio de la cortesía verbal. A las categorías acuñadas por Bravo para el ámbito de la cortesía, definidas como autonomía y afiliación (Bravo, 2003), Kaul de Marlangeon (2005) opone para el sector de la descortesía los conceptos de afiliación exacerbada y refractariedad.

La autonomía "abarca todos aquellos comportamientos que están relacionados con una persona que desea verse y ser vista por los demás como un individuo con contorno propio dentro del grupo". La afiliación "agrupa aquellos comportamientos en los cuales se refleja cómo una persona desea verse y ser vista por los demás en cuanto a aquellas características que la identifican con el grupo" (Bravo, 2003: 106).

Kaul de Marlangeon (2005) complejiza este modelo al introducir los conceptos de afiliación exacerbada y refractariedad, como motivaciones de lo que la autora ya ha definido como descortesía de fustigación. Al concepto de afiliación en el seno de la cortesía le opone el de afiliación exacerbada en el sector de la 
descortesía y la define como la actitud de "verse y ser visto como adepto al grupo (...) al punto de escoger la descortesía en su defensa" (Kaul de Marlangeon, 2005: 303). Por otra parte, al concepto de autonomía en el seno de la cortesía le opone el de refractariedad en el sector de la descortesía, entendida como "la autonomía exacerbada de verse y ser visto como opositor al grupo" con la intención de expresar que se "está en una actitud refractaria respecto de aquello que suscita (la) oposición" (Kaul de Marlangeon, 2005: 303).

Cada una de estas motivaciones presenta un aspecto defensivo y otro ofensivo. Defensivo de los valores que son propios del hablante en el caso de la refractariedad y de los valores del grupo al que adhiere en el de la afiliación exacerbada. Ofensivo de los valores del grupo al cual se opone en el caso de la refractariedad y de los valores opuestos al grupo al que adhiere en el de la afiliación exacerbada.

En 2008, Kaul de Marlangeon publica una tipología del comportamiento verbal descortés en español en la que establece una escala de tipos de descortesía en grado ascendente tomando como criterios la intencionalidad del hablante y la magnitud de la lesión que inflige sobre su interlocutor. Finalmente, en las investigaciones más recientes de la autora se analizan las formas de tratamiento en dos corpus diferentes.

La primera de estas investigaciones (Kaul de Marlangeon, 2010) describe los tratamientos de segunda persona y sus connotaciones asociadas a la cortesía en el discurso de propaganda. La autora advierte que en estos contextos el uso de la alternancia está condicionado por las fuerzas de cortesía que estas formas pronominales portan. Ya sea para servir como estrategia de afiliación y "untar la imagen de los potenciales clientes a fin de tornarlos consumidores del producto" o como estrategia de autonomía y operar como resguardo de la imagen del emisor para "propender al cumplimiento de compromisos" (Kaul de Marlangeon, 2010: 995).

En el segundo artículo (Kaul de Marlangeon, 2011) la autora examina varios ejemplos en los que la alternancia en las formas de tratamiento funciona como una estrategia en las manos del emisor para manejar su relación con el receptor. Exhibe la alternancia, en el sentido de variación pronominal ocurrente en un mismo texto y con relación al mismo interlocutor, como un mecanismo a disposición del usuario para canalizar sus intenciones corteses o descorteses en determinadas situaciones bastante estandarizadas dentro de la cultura. Avanza hacia una conceptualización de la alternancia como estrategia de variación pragmática portadora de sentidos adicionales de naturaleza intracultural.

Las situaciones tipificadas por la autora en esta última investigación resultaron muy orientadoras en el trabajo sobre nuestro corpus. En muchos casos, los ejemplos de variación pragmática que identificamos en las obras pudieron ser analizados bajo el amparo de esa clasificación. Pero en otros, consideramos oportuno introducir nuevas categorías que nos permitieran clasificar los ejemplos de nuestro corpus que no habían sido contemplados por el modelo original.

\section{Metodología}

\subsection{Consideraciones generales}

Retomaremos en este apartado algunas consideraciones metodológicas que realiza Lavandera (2014) a propósito del estudio de la variación. La primera tiene que ver 
con la delimitación de la unidad de análisis, que en este caso no será la oración sino que tomaremos fragmentos más extensos del discurso. Esta decisión metodológica se relaciona con el interés de nuestra investigación que es determinar la implicancia pragmática del empleo de la alternancia en las formas de tratamiento como estrategia en manos del emisor para comunicar mensajes diferentes. Por ese motivo necesitamos apelar a fragmentos del discurso más extensos en los que la sustitución de una forma alternante por otra que pertenece al mismo paradigma produzca modificaciones en el sentido del mensaje.

Para delimitar estos fragmentos hemos seguido un criterio metodológico relacionado con el propósito de nuestra investigación. Dado que nuestra intención es analizar ejemplos de variación pragmática en las formas de tratamiento, seleccionamos aquellos fragmentos del discurso en los que se materializa el fenómeno de la alternancia. De modo que sus límites no necesariamente coinciden con los del enunciado ni los de otras unidades supraoracionales.

La segunda consideración sostiene que la variación en el discurso tiene que estudiarse tanto en el eje paradigmático como en el eje sintagmático, es decir, cuando una forma sustituye a su alternante en el mismo espacio del discurso y también cuando se produce el paso del empleo de una forma gramatical a otra del mismo sistema de manera secuencial. En nuestro trabajo de investigación nos ocuparemos solo de la variación en el eje sintagmático porque nos interesa observar la variación pronominal ocurrente en un mismo texto y con relación al mismo interlocutor.

Hemos decidido prescindir del análisis en el eje paradigmático porque su estudio queda fuera de lo que Kaul de Marlangeon define como variación pragmática de las formas de tratamiento: "cuando el hablante usa la alternancia en un mismo texto dirigido al mismo receptor" (Kaul de Marlangeon, 2011, p. 224).

Como última consideración, Lavandera (2014) advierte que:

un único ejemplo expresivamente eficaz de una forma lingüística que encuentra su lugar significativo en la configuración particular del texto en que aparece, puede revelar más acerca de la contribución semántica que esta forma es potencialmente capaz de hacer al discurso y acerca del sistema a que pertenece, que la descripción de los contextos en que la misma forma resulta más frecuente y, por ende, está menos marcada (Lavandera, 2014, p.113).

Este hecho explica por qué hemos optado por una metodología cualitativa, que resulta más propicia para la descripción y el análisis exhaustivo de un único ejemplo seleccionado adecuadamente que la metodología cuantitativa, en la que se requiere de múltiples casos para establecer generalizaciones.

Por otro lado, una investigación cualitativa tiene la característica de que la revisión de la literatura y la recolección de datos no son necesariamente posteriores a la elaboración de hipótesis y preguntas de investigación, sino que se trata de un proceso dinámico en el que las preguntas e hipótesis pueden afinarse en cualquier instancia del proceso de investigación. En estos casos se procede de acuerdo con una lógica inductiva, el investigador comienza observando el mundo social y en función de lo que ve desarrolla una teoría coherente con estos datos. La acción indagatoria es esencialmente interpretativa, como señala Hernández Sampieri (2010, p. 10): "El enfoque cualitativo puede concebirse como un conjunto de prácticas interpretativas que hacen al mundo 'visible', lo transforman y convierten 
en una serie de representaciones en forma de observaciones, anotaciones, grabaciones y documentos".

Caracterizamos el presente proceso de investigación como cualitativo, exploratorio y descriptivo. Partimos del análisis de las fuentes para construir las categorías teóricas que nos permitan interpretar los ejemplos de nuestro corpus y avanzar hacia una clasificación.

\subsection{Defensa de un corpus literario de análisis}

El corpus que construimos para nuestra investigación está compuesto en su totalidad por textos dramáticos argentinos de principios del siglo XX en los que pretendemos analizar la dimensión pragmática de las formas de tratamiento. Todos ellos se inscriben en una corriente realista y pertenecen a lo que algunos estudiosos denominan como el "período más intenso y popular del teatro argentino" (Ricci, 2003 , p. 2). Son las obras que inauguran los géneros populares que vienen con la ola inmigratoria, como el sainete y el grotesco ${ }^{1}$, y ponen en el centro de la escena tanto la vida diaria de la ciudad con sus personajes populares, como los modos expresivos característicos de la época, que son el lunfardo y el cocoliche. Este teatro se convierte en un espejo de la realidad y por ese motivo encontramos en sus líneas numerosos ejemplos que ilustran a todas luces los modos de decir característicos de esta variedad dialectal rioplatense sincrónicamente situada.

El teatro vocacional, de oficio, como se conoce a este repertorio dramático de corte popular y comercial, no solo se había convertido en una epidemia popular por la respuesta favorable del público, que asistía de lunes a lunes a las representaciones de las compañías teatrales y compraba semana tras semana los textos que se vendían en kioscos y librerías, sino ante todo porque a través del teatro se construía la identidad nacional de una Argentina incipiente que se concebía a sí misma como 'crisol de razas'.

Esta relación de toma y daca entre el teatro realista y el lenguaje popular, en oposición al teatro de arte, independiente, con repertorio propio, es la que nos permite conocer cuáles eran en ese momento histórico las pautas socioculturales de la comunidad rioplatense que permiten explicar el empleo de la alternancia en las formas de tratamiento como estrategia pragmática.

A propósito del empleo de la literatura -y más precisamente de los textos dramáticos-para analizar aspectos pragmáticos también consideramos invaluables los aportes de Gancedo Ruiz (2016). En ese trabajo, la autora esgrime tres argumentos que justifican el empleo de obras dramáticas en estudios pragmáticos.

\footnotetext{
${ }^{1}$ El sainete criollo y el grotesco son los géneros con los que se consolida el teatro nacional a principios del siglo XX. Se trata de un teatro de corte popular y realista que representa la vida en los conventillos, viviendas comunes para la época. Son obras cómicas que tienen como protagonista al inmigrante recién llegado que vaga en busca de una identidad argentina. Aunque ambos géneros se originan en la misma época y representan un mismo ámbito social, es posible señalar algunas diferencias. El sainete criollo transcurre en espacios públicos, como la calle o el patio de un conventillo, escenifica varios conflictos superficiales y su intención cómica está explícita en la obra. Los personajes suelen ser bastante estereotipados y su propósito es recreativo. El grotesco, en cambio, es un género que presenta otra complejidad y otra profundidad dramática. Generalmente transcurre en espacios privados, como una casa familiar o la habitación de una casa. Representa un único conflicto de gran profundidad dramática y la intención cómica no está explícita, sino que se llega a ella a través de la tragedia: lo cómico aparece como descarga frente a la situación de angustia que atraviesa el héroe. Cada uno de los personajes revela una profundidad psicológica que lo aleja de los estereotipos y el propósito de la obra es desencadenar en el público una profunda reflexión moral (Ricci, 2003).
} 
Ella los denomina argumentos "histórico-socioculturales", "interaccionales" y "sociolingüísticos". El primero descansa en el hecho de que ninguna obra literaria es una isla ni está aislada de su contexto de producción. Muy por el contrario, todo texto dramático se encuentra fuertemente condicionado por el contexto histórico y sociocultural en el que fue producido y a menudo refleja la percepción y sensibilidad de los miembros de la cultura, su comportamiento social y visión de mundo.

El segundo argumento, al que la autora se refiere como factores interaccionales, alude a la fuerte carga dialógica que caracteriza al género dramático y permite analizar las emisiones de los hablantes, así como el efecto comunicativo que tienen en sus receptores, sin la mediación de un narrador. Por otro lado, la descripción de las escenas permite conocer en detalle la situación comunicativa y su contexto, aportando todos los elementos que se necesitan para un análisis pragmático.

Finalmente, el argumento sociolingüístico se refiere al hecho de que la escritura dramática puede proporcionar datos sobre la variación diastrática al reflejar los diferentes dialectos sociales de una época para caracterizar social y moralmente a sus personajes. Estos argumentos confirman la tesis de Coseriu que retoma Kaul de Marlangeon (2003, p. 5) en función de la cual la literatura no constituye una desviación o un uso parasitario del lenguaje, sino que "representa la plena funcionalidad del lenguaje".

\section{Análisis}

Retomando la tipología acunada por Kaul de Marlangeon (2011) hemos realizado una primera clasificación de los ejemplos de alternancia en las formas de tratamiento que conforman nuestro corpus en tres grandes grupos: aquellos que evidencian variación pragmática en el ámbito de la cortesía, los que manifiestan variación pragmática en el ámbito de la descortesía y, finalmente, los casos en los que la alternancia en las formas de tratamiento no constituye variación pragmática.

\subsection{Variación pragmática en el ámbito de la cortesía}

La alternancia en las formas de tratamiento en el ámbito de la cortesía puede estar motivada por la necesidad de afiliación o de autonomía. En el primer caso, el emisor desea se percibido por su interlocutor como miembro de la clase a la que este pertenece y utiliza el mecanismo de la alternancia como una estrategia de acercamiento. En el segundo caso, el emisor pretende dejar de ser percibido por su interlocutor como un miembro del grupo con el que se lo quiere vincular y emplea la alternancia como mecanismo de distanciamiento en resguardo de su propia imagen. Los ejemplos que transcribimos a continuación ilustran el funcionamiento de estos fenómenos.

En el primer ejemplo, el diálogo reproduce la interacción entre el propietario de una vivienda y su inquilino. Este último tiene intenciones de comprar la propiedad. En el segundo ejemplo, asistimos al intercambio entre dos personajes del mismo rango social que ocupan un lugar de subalternidad respecto de quienes serían sus líderes.

1) Inocencio: ¡Ah!... ¡Pero usted es propietario! No delira con el problema de la vivienda... la tranquilidad... el porvenir al bolsillo. ¡Ah!... ¡Si yo tuviese mi casa! (...) Inocencio: Y cómo no la vas a vender si te la pago bien. 
Pippo: Me hace reír usted... ¡Con lo que gana!... No... No me la puede comprar (Darthés, Camilo, 1926, “El sueño de la casa propia”, p. 82, 83).

En esta primera línea, el inquilino se refiere al propietario con la fórmula de respeto usted, que era lo esperable en esa época entre dos sujetos de diferente rango social que no estaban unidos por un vínculo de afecto y confianza. Sin embargo, en la segunda línea, Inocencio abandona el registro formal y se dirige a Pippo con el pronombre vos, manifiesto en la desinencia verbal: vas, así como en la forma pronominal con función de objeto te, que pertenece al paradigma de voseo.

En este caso, la alternancia en las formas de tratamientos está motivada por la necesidad de afiliación de Inocencio al grupo de los propietarios/vendedores al que pertenece Pippo. El objetivo del emisor es inducir en el vendedor la idea de que ambos pertenecen a la misma clase social; así lo manipula y pretende persuadirlo de venderle la propiedad.

2) Ecuménico: Mirá, hermano: no te voy a poder servir.

Palmero: ¡Pucha que hablás pronto y claro! ¿Y por qué, si puede saberse?

Ecuménico: Toy distanciao de don Alejo. Es decir, se me ha distanciao, que no es lo mismo, aunque pal caso resulte así.

Palmero: ¿Así que andás con el doctor Clemente Ordoñez, ahura?

Ecuménico: ¿Qué ha dicho, mi sargento? ¿Cómo ha dicho? ¡Ecuménico López no tiene vueltas! A ver si te lo aprendes pal resto de tu vida (Eichelbaum, Samuel, 1940, "Un guapo del 900", p. 14-15).

Como se espera de dos personas que mantienen una relación de confianza cimentada en lazos de simetría, entre estos personajes predomina un tratamiento informal. Ese uso de confianza se advierte en la desinencia de los verbos: hablás, andás, aprendés, en el pronombre en caso objetivo te que aparece en la primera línea de Ecuménico: no te voy a poder servir, y en el dativo de interés de la línea final: te lo aprendés pal resto de tu vida.

Sin embargo, en la última línea de diálogo, Ecuménico abandona repentinamente la fórmula de confianza y responde a la pregunta de Palmero valiéndose del tratamiento de respeto marcado por el pronombre usted, que se encuentra en la desinencia verbal del tiempo compuesto: ha dicho. Esta alternancia en las formas de tratamiento puede ser interpretada como una estrategia de resguardo de la propia imagen motivada por la necesidad de autonomía del emisor que desea ser percibido por su interlocutor como un individuo separado del grupo de los traidores que se han ido de un bando a otro y ahora sirven a quien antes era su adversario.

Palmero ha interpretado que el distanciamiento de Ecuménico y don Alejo se debe a que aquél está al servicio de Clemente Ordoñez, oponente del primero; y a Ecuménico le urge desmentir esa conclusión errónea que lo asimila al grupo de traidores o 'panqueques', en la jerga de los compadritos. Para marcar su autonomía respecto de este último grupo, el emisor se vale de la alternancia en las formas de tratamiento como estrategia para resguardar su imagen de cualquier insinuación de deslealtad.

En nuestro corpus también pudimos reconocer múltiples ejemplos de alternancia en las formas de tratamiento por adecuación a una situación comunicativa estandarizada dentro de la cultura, como es la de cortejo. Cuando un personaje masculino corteja a otro personaje femenino es habitual que abandone el trato formal y emplee expresiones que pertenecen al paradigma de confianza para 
referirse a su interlocutora. Esta variación pragmática está motivada por las características de la situación comunicativa en la que tiene lugar la interacción, ya sea "por la naturaleza de lo que se dice o por las circunstancias que acompañan lo que se dice" (Kaul de Marlangeon, 2011, p. 228).

Para ilustrarlo, transcribimos un ejemplo que reproduce la interacción entre Prudencia, hija mayor de Don Zoilo (gaucho de fines del siglo XIX) y Juan Luis, el propietario de la estancia. Ambos tienen un amorío, aunque Prudencia está comprometida con Aniceto, ahijado de Don Zoilo. Sus interacciones tienen lugar en secreto, a espaldas de los otros personajes, por la naturaleza clandestina de la relación que mantienen.

3) Juan Luis: Buenas tardes. ¡No se vaya! ¿Cómo está?

Prudencia: ¡Ay, Jesús! ¡Cómo me encuentra!...

Juan Luis: ¡Encantadora te encuentro, monísima, mi vidita!

Prudencia: ¡No... no!... Déjeme... Váyase... ¡Tata está ahí!

Juan Luis: ¿Y qué tiene? ¡Dormirá! ¡Vení, prenda! (Sánchez, Florencio, 1905,

"Barranca abajo", p. 71).

La forma de tratamiento habitual entre ambos es la de respeto, como se desprende de la primera línea de Juan Luis en la que se vale del pronombre usted que se encuentra en la desinencia de los verbos: vaya, está y en la forma refleja se para referirse a Prudencia. Ella nunca abandona el registro formal, ni siquiera cuando Juan Luis la toma por sorpresa e intenta un acercamiento físico. Él, en cambio, abandona el registro formal en la situación de cortejo y se vale de los vocativos mi vidita y prenda (apelativo cariñoso con el sentido de aquello que se aprecia intensamente) que indican una relación de confianza y afecto con su interlocutora. La misma alternancia se observa en las formas de tratamiento que pasan del ustedeo al voseo, presente en el pronombre en caso objetivo: te y en la desinencia del verbo: vení, que además se encuentra en modo imperativo sin atenuación.

Esta variación en las formas de tratamiento se explica si tenemos en cuenta, por una parte, las circunstancias que acompañan a lo que se dice: el encuentro furtivo entre dos amantes clandestinos y, por otra, la naturaleza de lo que se dice: halagos y expresiones de afecto que tienen por finalidad persuadir a Prudencia para que deje de poner frenos a la posibilidad del contacto físico.

El último fenómeno de alternancia al que vamos a aludir en el campo de la cortesía es el que está motivado por un cambio situacional en la relación de poder. En estos casos, aunque exista una relación de mutua confianza entre los interlocutores, la asimetría del rol que ejerce uno de ellos sobre el otro se impone en la selección de la forma de tratamiento.

Así se observa en el siguiente ejemplo que reproduce el intercambio entre Don Zoilo y el sargento, un oficial de la policía.

4) Don Zoilo: ¿Qué andás queriendo vos acá?

Sargento: ¡Güen día, viejo! Aquí andamos. Este... Vengo a citarlo.

Don Zoilo: ¿A mí?

Sargento: Es verdad.

Don Zoilo: ¿Pa qué?

Sargento: Vaya a saber uno... Lo mandan y va.

(...)

Don Zoilo: Está bien, sargento. Lléveme no más. ¿Tiene orden de atarme? Proceda no más.

Sargento: ¡Qué esperanza! Y aunque tuviese. Yo no ato cristiano manso. 
Don Zoilo: ¿No sabe qué hay contra mí?

Sargento: Decían que una denuncia de un vecino.

(...)

Don Zoilo: Cuando guste... Tengo el caballo ensillao (Sánchez, Florencio, 1905,

"Barranca abajo", p. 93).

En la primera línea de diálogo Don Zoilo emplea el trato de confianza y se refiere al sargento con el pronombre vos y la forma verbal andas (voseo verbal). La respuesta de este último evidencia que existe entre ambos una relación interpersonal de confianza mutua, posiblemente, por ser los dos nativos de la misma región. También comprobamos que el sargento lo trata de usted, aunque Don Zoilo haya preferido el voseo, lo cual se explica si tenemos en cuenta la diferencia de edad entre un personaje y el otro. Don Zoilo podría ser el padre de aquél y por ese motivo el tratamiento que recibe de parte del policía es de respeto y consideración. En el inicio de este intercambio, el vínculo que los une prevalece por encima de la asimetría impuesta por la diferencia de roles.

Sin embargo, cuando con rodeos y vacilaciones el sargento reconoce que ha ido al rancho en pleno ejercicio de sus funciones a buscar a Don Zoilo por motivo de una citación, la forma de tratamiento con la que el gaucho se dirige a él se modifica radicalmente. A partir de ese momento, Don Zoilo no volverá a usar expresiones voseantes. Se va a referir a él como sargento y empleará verbos que por su desinencia verbal pertenecen al paradigma de ustedeo: lléveme, tiene, proceda, sabe, guste.

En este caso, no es el policía quien modifica su registro con una intención intimidatoria, sino el personaje del gaucho, que pasa del tratamiento de confianza inicial a la formalidad del ustedeo, reforzada por el empleo del vocativo sargento.

Esta alternancia en las formas de tratamiento puede interpretarse como una variación pragmática operada por el cambio situacional en la relación de poder. Don Zoilo comprende que más allá del vínculo personal que lo une con su coterráneo, debe respetar la autoridad de su investidura como oficial de la policía y manifiesta esa comprensión instaurando una distancia en el trato.

\subsection{Variación pragmática en el ámbito de la descortesía}

En el ámbito de la descortesía, la alternancia en las formas de tratamiento también funciona como un mecanismo de variación pragmática. A partir del análisis de nuestro corpus hemos documentado con cierta persistencia el fenómeno de ruptura de la expectativa respecto del trato para instalar distancia. Esto habitualmente sucede entre dos interlocutores que mantienen un grado de intimidad en función del cual la fórmula de tratamiento que se percibe como natural es la de confianza. Sin embargo, uno de ellos decide transgredir esta expectativa y emplear un tratamiento formal con la finalidad de instalar cierta distancia que menoscaba la imagen de su interlocutor. En estos casos, la alternancia en las formas de tratamiento constituye un acto de descortesía (Kaul de Marlangeon, 2011: 232).

Para ilustrarlo, seleccionamos un ejemplo que reproduce la interacción entre dos concubinos: Claudia y Pichín. La relación entre esta pareja se vuelve cada vez más tensa hasta que llega a su fin en el desenlace de la obra.

5) Pichin: ¿Ande vas?

Claudia: ;Donde a usted no le importa!

Pichin: ¡Eh!... ¡Pará el carro!... ¡Qué retobada estás, vieja!...

Claudia: Dejáme salir... (Sánchez, Florencio, 1902, "Canillita”, p. 67). 
En el diálogo que acabamos de transcribir Claudia planea salir de la casa sin dar explicaciones y cuando Pichin se las pide ella responde de una manera que evidencia la distancia que se ha venido instaurando entre ellos desde el comienzo de la obra.

Entre ambos personajes existe una relación interpersonal de confianza mutua, además de un grado de intimidad que está dado por la relación de pareja que mantienen, de modo que el tratamiento esperable sería el de voseo. Así se dirige Pichin a Claudia, como se deduce de la desinencia de los verbos: vas, pará, estás. Y también Claudia emplea expresiones voseantes en su última línea: dejáme (voseo verbal).

Sin embargo, cuando él le pregunta a dónde va, ella responde: Donde a usted no le importa y con esta afirmación, no solo deja claro que no piensa darle explicaciones, sino que además rompe la expectativa del trato informal al utilizar el pronombre usted y la forma pronominal en caso objetivo le, que también pertenece al paradigma de ustedeo.

Al transgredir las convenciones en el trato que se aguardarían como naturales por parte de su interlocutor, Claudia instaura una distancia que no deja lugar para que Pichin le haga más preguntas o intente impedir que ella siga con sus planes. Es una manera muy efectiva de demostrarle a través del lenguaje que él ya no tiene más poder sobre sus actos y que ella ahora está por su cuenta.

Otro caso de variación pragmática en el ámbito de la descortesía que aparece con mucha frecuencia en las obras de nuestro corpus es el que introduce la agresión en un acto de descortesía de fustigación (Kaul de Marlangeon, 2011: 234). Esto sucede cuando, después de un previo tratamiento de usted aparece el vos como punto de inflexión que señala el momento en el cual el hablante ha decidido dejar a un lado cualquier vestigio de respeto hacia su interlocutor y valerse de la agresión verbal para dañar deliberadamente la imagen de aquel.

El enfrentamiento entre los participantes del diálogo se ha ido configurando desde el comienzo de su intercambio y de manera progresiva la situación se ha vuelto cada vez más tensa, hasta que la agresión verbal ha irrumpido como el desenlace más previsible. De hecho, en muchos de los casos, el acto verbal descortés está acompañado por una amenaza de agresión física que anticipa el pasaje de un enfrentamiento verbal a una pelea cuerpo a cuerpo. El carácter deliberado de la agresión verbal, así como la intensidad de la lesión infligida por el hablante a su interlocutor explican que la discusión derive en la violencia física.

A continuación transcribimos un ejemplo que reproduce el enfrentamiento entre dos vecinas de un conventillo y tiene la particularidad de evidenciar actos de descortesía en las dos direcciones: del hablante hacia el oyente y viceversa.

6) Vecina $1^{\circ}$ : Diga: ¿no tiene más que hacer que poner su ropa encima de la mía? Vecina $2^{\circ}:(\ldots)$ ¿Cuánto paga, doña, por el alquiler del alambre?

Vecina $1^{\circ}$ : Lo que a usted no le importa $(. .$.$) ¡Y haga el favor de sacar esos trapos$ sucios de ahí!...

Vecina $2^{\circ}$ : ¡Trapos sucios!... ¡Trapos sucios!... ¡Qué más tequisieras para un día de fiesta!

(...)

Vecina $1^{\circ}:$ (...) ¡Te viá enseñar, arrastrada!... ¡Ladrona!... ¡Escracho!... (Sánchez, Florencio, 1902, "Canillita", p. 64).

El intercambio se inicia con el reproche de la vecina 1, que está molesta porque la vecina 2 ha tendido la ropa encima de la suya; a lo cual ésta responde con 
ironía: ¿cuánto paga, doña, por el alquiler del alambre? Lo que comenzó con un reproche continúa con un acto de habla indirecto que asume la forma de una interrogación.

Al iniciar el intercambio con una reprimenda, la vecina 1 se ha arrogado poder sobre su interlocutora. Pero con su respuesta, la vecina 2 ha demostrado que ese reclamo de poder ha sido un fracaso. Al fin y al cabo, las dos son inquilinas en la misma dependencia y tienen los mismos derechos. Entre ambas existe una relación de simetría que inhabilita el ejercicio de poder de una sobre otra sin incurrir en un comportamiento verbal descortés.

La contienda continúa, pero todavía ninguno de sus participantes ha abandonado el tratamiento formal. Hasta que la vecina 1 se refiere a la ropa de la vecina 2 con la expresión despectiva de trapos sucios. Esta agresión deliberada desencadena a modo de represalia la aparición del vos, para indicar que se ha llegado al límite de lo tolerable. Trapos sucios... iQué más te quisieras para un día de fiestas!, responde la vecina 2 al agravio de la primera. Tanto la desinencia del verbo como el pronombre te pertenecen al paradigma de voseo. La vecina 1 profundiza el enfrentamiento y acompaña el abandono del tratamiento usted con una amenaza: ¡Te viá enseñar, arrastrada! La intensidad de la agresión se acrecienta con el uso de los adjetivos calificativos ladrona y escracho, que acentúan la lesión esgrimida sobre la imagen del interlocutor.

\subsection{Ausencia de variación pragmática}

Para concluir nuestro análisis queremos mencionar la posibilidad, ya señalada por Kaul de Marlangeon (2011), de que la alternancia en las formas de tratamiento no constituya variación pragmática cuando es constante según roles. La NGLE (2009, p. 1250) denomina este fenómeno como tratamiento asimétrico y tiene lugar cuando el emisor utiliza formas de respeto con su interlocutor pero recibe de aquel un trato de confianza, o viceversa, debido a la edad o a la jerarquía que los separa.

En el ejemplo que identificamos en nuestro corpus, la alternancia constante no depende de los roles o de la jerarquía de los personajes, porque se trata de dos jóvenes de la misma edad. Lo que determina la elección del vos y del usted son las convenciones socio-históricas del contexto de pertenencia de cada uno. Edy es un joven de la década del setenta y Jocky es una joven de la década del cincuenta, que coinciden circunstancialmente por los efectos de un viaje en el tiempo. A continuación transcribimos un breve fragmento de su intercambio.

7) Jocky: ¡Déjeme! ¿Qué se ha creído? ¿Cómo se atreve a hablarme así?

Edy: ¿Y cómo debo hablarte? (Cuzzani, Agustín, 1975, “Complejísima”, p. 24).

En estas dos líneas podemos identificar que el intercambio se inicia con una alternancia constante en las formas de tratamiento que cada uno de los personajes emplea para referirse al otro. Jocky usa el usted y Edy el vos. Esta diferencia tiene sentido si pensamos en las transformaciones que ha experimentado a lo largo de estas dos décadas la dimensión pragmática de las formas de tratamiento.

Las formas de tratamiento forman parte del conjunto de reglas sociales que rigen el comportamiento verbal de los miembros de una comunidad y son portadoras de sentidos socialmente definidos (Medina López, 2005, p. 99), que varían a través del tiempo. A propósito de esta transformación, la NGLE (2009, p. 1252) ha reconocido como uno de los fenómenos más característicos del siglo XX el predominio de las formas simétricas e informales, que condujo a una expansión del 
vos y a un retraimiento del usted. En la primera mitad del siglo esto se debió a los movimientos políticos igualitarios que contribuyeron a la extensión progresiva de las formas de confianza; mientras que en la segunda mitad ha tenido mayor influencia en este proceso el valor que se otorga en el mundo moderno a la juventud $\mathrm{y}$ al hecho de ser joven.

A medida que nos adentramos en el siglo $\mathrm{XX}$, la utilización del vos va ganando cada vez más espacio en detrimento del usted. Y este fenómeno queda claro en el intercambio entre los personajes del ejemplo. Jocky interpreta como un atrevimiento que Edy emplee el tratamiento de confianza para referirse a ella, que es una desconocida. Edy le pregunta: ¿Y cómo debo hablarte?, dejando claro que no comprende su molestia y tampoco concibe otra forma de tratamiento posible. Dos décadas median entre un personaje y el otro, pero la dimensión pragmática de las formas de tratamiento se ha ido modificando progresivamente hasta disminuir en buena medida el uso del usted.

Aunque la alternancia constante según el contexto sociohistórico de pertenencia no constituye variación pragmática, sí reviste un comportamiento verbal descortés. Porque de acuerdo con las convenciones sociales de la década a la que pertenece Jocky, el tratamiento que le dispensa Edy es entendido como un acto de descortesía no esgrimido, sino tan solo no evitado por escatima involuntaria de la cortesía esperada por el oyente (Kaul de Marlangeon, 2008), que en este caso no solo espera sino que también reclama el tratamiento de respeto.

\section{Conclusiones}

Los diferentes ejemplos de alternancia en las formas de tratamiento que hemos analizado en nuestro corpus demuestran que este fenómeno gramatical, asociado al paradigma pronominal de segunda persona del singular, no es inocente desde una perspectiva pragmática. La descripción pormenorizada de los diferentes factores de índole sociocultural que permiten justificar esa variación gramatical en el eje sintagmático demuestra que la alternancia en las formas de tratamiento puede convertirse en un recurso pragmático del que se vale el hablante para comunicar sus intenciones más o menos (des)corteses.

En el campo de la cortesía, registramos los siguientes casos de variación pragmática: como estrategia motivada por la necesidad de autonomía o afiliación, por adecuación a la situación comunicativa de cortejo y, finalmente, por cambio situacional en la relación de poder. En el ámbito de la descortesía se destacan por su frecuencia: la ruptura de la expectativa respecto del trato para instalar distancia y la variación pragmática que introduce la agresión en un acto de descortesía de fustigación.

También comprobamos que la ausencia de variación pragmática puede canalizar las intenciones de cortesía y descortesía del hablante, convirtiéndose en un comportamiento estratégico que es portador de un sentido adicional intracultural. Así sucede en el último apartado, en el que la ausencia de variación pragmática se produce por alternancia constante en las formas de tratamiento según el contexto socio-histórico de pertenencia de los personajes.

\section{Referencias}

\section{Referencias primarias}

1. Cuzzani, A. A. (1975 [2007]] Complejísima. Buenos Aires: Ediciones Colihue. 
2. Darthés, C. A. (1983 [1926]) El sueño de la casa propia. Buenos Aires: Ediciones Culturales Argentinas.

3. Eichelbaum, S. A. (1968 [1940]) Un guapo del 900. Buenos Aires: Centro Editor de América Latina.

4. Sánchez, F. A. (1987 [1902]] Canillita. Buenos Aires: Centro Editor de América Latina.

5. Sánchez, F. A. (1987 [1905]) Barranca abajo. Buenos Aires: Centro Editor de América Latina.

\section{Referencias secundarias}

1. Aiola, N. A. y Degli Uomini, M. B. (2014): El pronombre como clase de palabras. Río Cuarto: UniRío Editora.

2. Bravo, D. A. (2003): Actividades de cortesía, imagen social y contextos socioculturales: una introducción. En Bravo, D. A. (Ed.) Actas del I Coloquio Internacional del Programa EDICE (pp. 98-108). Estocolmo: Programa Edice.

3. Bravo, D. A. (2005): Pragmática, sociopragmática y pragmática sociocultural del discurso de la cortesía. En Bravo, D. A. (Ed.) Estudios de la (des)cortesía en español. Categorías conceptuales y aplicaciones a corpora orales y escritos (pp. 31-68). Buenos Aires: Editorial Dunken.

4. Fontanella de Weimberg, B. A. (1999): Sistemas pronominales de tratamiento usados en el mundo hispánico. En Bosque, I. y Demonte, V. (Ed.) Gramática descriptiva de la lengua española (pp. 1400-1425). Madrid: Espasa Calpe.

5. Gancedo Ruíz, M. A. (2016): El texto dramático literario como corpus para el análisis histórico de las actividades de imagen. Textos en proceso, 2, pp. 162-173. DOI: https://doi.org/10.17710/tep.2016.2.1.8gancedoruiz

6. Hernández Sampieri, R. A. (2010): Metodología de le investigación. Ciudad de México: McGraw-Hill.

7. Kaul de Marlangeon, S. A. (2003): La fuerza de cortesía- descortesía y sus estrategias en el discurso tanguero de la década del '20. Estocolmo: Programa Edice.

8. Kaul de Marlangeon, S. A. (2005): Descortesía de fustigación por afiliación exacerbada o refractariedad. En Bravo, D. A. (Ed.) Estudios de la (des)cortesía en español. Categorías conceptuales y aplicaciones a corpora orales y escritos (pp. 299-315). Buenos Aires: Editorial Dunken.

9. Kaul de Marlangeon, S. A. (2008): Tipología del comportamiento verbal descortés en español. En Briz, A. et al. (Ed.), Actas del III Coloquio Internacional del Programa EDICE (pp. 254-266). Valencia: Universidad de Valencia.

10. Kaul de Marlangeon, S. A. (2010) Voseo, ustedeo y cortesía verbal en folletos de propaganda argentinos. En Hummel, M. A., Kluge, B. B. y Vázquez Laslop, M. C. (Ed.), Formas y fórmulas de tratamiento en el mundo hispánico (pp. 995-1011). Ciudad de México: Colegio de México.

11. Kaul de Marlangeon, S. A. (2011): Voseo/ustedeo argentinos: su variación pragmática intralingüe e intracultural. En García, C. A. y Placencia, M. B. (Ed.) Estudios de variación pragmática en español (pp. 217-241). Buenos Aires: Editorial Dunken.

12. Lavandera, B. A. (2014): Variación y significado. Y discurso. Buenos Aires: Editorial Paidós.

13. Medina López, J. A. (2005): Variación sociolingüística en las formas de trato. El análisis probabilístico según los datos del español de Canarias en Murillo Medrano, J. A. (Ed.), Actas del II Coloquio Internacional del Programa EDICE (pp. 97-113). Estocolmo: Programa Edice.

14. Real Academia Española (2009): Nueva gramática de la lengua española. Madrid: Espasa-Calpe.

15. Ricci, J. A. (2003): Momentos del Teatro Argentino. Texturas. Estudios interdisciplinarios sobre el discurso, 3(3), pp. 161-182. DOI: https://doi.org/10.14409/texturas.v1i3.2809 